\title{
Physico-chemical properties of Brazilian cocoa butter and industrial blends. Part II - Microstructure, polymorphic behavior and crystallization characteristics
}

\author{
By A.P.B. Ribeiro ${ }^{a,}$, R. Corrêa Basso ${ }^{b}$, L.A.G. Gonçalves ${ }^{b}$, L.A. Gioiellic, A. Oliveira dos Santos ${ }^{d}$, \\ L. Pavie Cardoso ${ }^{\mathrm{e}}$ and T. Guenter Kieckbusch ${ }^{\mathrm{a}}$
}

\author{
${ }^{a}$ School of Chemical Engineering, University of Campinas, Campinas, Brazil. \\ ${ }^{\mathrm{b}}$ Faculty of Food Engineering, University of Campinas, Campinas, Brazil. \\ ${ }^{c}$ Faculty of Pharmaceutical Sciences, University of São Paulo, São Paulo, Brazil. \\ ${ }^{d}$ Social Sciences, Health and Technology Center, University of Maranhão, Brazil. \\ ${ }^{\mathrm{e}}$ Institute of Physics Gleb Wataghin, University of Campinas, Campinas, Brazil. \\ ${ }^{*}$ Corresponding author: badanribeiro@yahoo.com.br
}

\section{RESUMEN}

Propiedades físico-químicas de la manteca de cacao de Brasil y mezclas industriales. Parte II - Microestructura, comportamiento polimórfico y características de la cristalización.

En este trabajo se presenta el comportamiento de la microestructura y la cristalización de mantecas de cacao representativas de las mezclas industriales, y de la manteca de cacao original de tres regiones geográficas diferentes de Brasil. Las muestras se evaluaron de acuerdo a la microestructura, la cinética de cristalización y el comportamiento polimórfico. La evaluación de estos parámetros nos permite establecer relaciones entre la composición química y el comportamiento de la cristalización de las muestras, así como las diferencias sobre la adecuación del potencial tecnológico e industrial para su aplicación en las regiones tropicales.

PALABRAS CLAVE: Cinética de la cristalización Manteca de cacao - Microestructura - Polimorfismo.

\section{SUMMARY}

Physicochemical properties of Brazilian cocoa butter and industrial blends. Part II Microstructure, polymorphic behavior and crystallization characteristics.

The microstructural behavior of industrial standardized cocoa butter samples and cocoa butter samples from three different Brazilian states is compared. The cocoa butters were characterized by their microstructural patterns, crystallization kinetics and polymorphic habits. The evaluation of these parameters aided in establishing relationships between the chemical compositions and crystallization behavior of the samples, as well as differentiating them in terms of technological and industrial potential for use in tropical regions.

KEY-WORDS: Cocoa butter - Crystallization kinetics Microstructure-Polymorphism.

\section{INTRODUCTION}

Cocoa butter is the distinctive ingredient of the chocolate industry and recognized as the most expensive and important constituent in all chocolate formulations (Shukla, 2006). Three main fatty acids found in the composition of cocoa butter are palmitic, stearic and oleic acids. Virtually all oleic acid is esterified in the central position of the glycerol molecule (sn-2), while saturated fatty acids are normally located in the $s n-1,3$ positions. This particularity characterizes cocoa butter by three main symmetric triacylglycerols (TAGs) in relation to the saturation/unsaturation aspect, represented by POP (1,3-dipalmitoyl-2-oleoyl-glycerol), POSt (1-palmitoyl-2-oleoyl-3-stearoyl-glycerol) and StOSt (1,3-diestearoyl-2-oleoyl-glycerol) species, which, summed up, may account for more than $75 \%$ of its composition in TAGs (Lipp and Anklam, 1998).

The crystallization behavior of lipids has important implications in the development of processed food products, whose physical attributes depend largely on fat crystal structures and properties such as consistency, plasticity, texture stability, sensorial features and visual appearance (Sato, 2001). Cocoa butter crystallization influences, particularly, the snap, brightness, melting sensation in the mouth combined with flavor release and stability during storage, all main characteristics that determine the quality of chocolate and similar products. These attributes are directly dependent on the melting and crystallization behavior, crystallization kinetics, degree of compatibility among TAGs and structure of the crystal network, which, in cocoa butter, are regulated by its complex polymorphic arrays (Awad and Marangoni, 2006; Foubert et al., 2007). Polymorphism can be defined in terms of the ability to exhibit different unit cell structures, resulting from different molecular packing. For cocoa butter, six polymorphic forms are verified as a result of its fairly homogeneous TAG composition, known as $\gamma, \alpha$, $\beta_{2}, \beta_{1}, \beta_{2}$ and $\beta_{1}$, in accordance with current nomenclature (McGauley and Marangoni, 2002). The nomenclature for cocoa butter polymorphs can also be found based on the Roman numbering system, where the forms I, II, III, IV, V and VI correspond to $\gamma, \alpha, \beta_{2}{ }^{\prime}, \beta_{1}{ }^{\prime}, \beta_{2}$ and $\beta_{1}$ polymorphs, respectively. 
Usually there are combinations of this terminology with Greek nomenclature. Forms I and II are obtained by rapid cooling at low temperatures, while forms III and IV are produced at moderate temperatures. Form $\mathrm{V}$ is associated with the desirable crystalline habit in chocolate. The crystalline modifications in cocoa butter, with the exception of form $\mathrm{VI}$, can be obtained directly from the liquid state, under proper cooling conditions. The transition $\mathrm{V} \rightarrow \mathrm{VI}$ is mediated only by solid-solid transformation and proceeds during the storage of chocolates (Loisel et al., 1998; Schenck and Peschar, 2004; Shi et al., 2005).

An understanding of the relationship between these parameters is essential to assess the aspects of quality and performance during the processing and storage of products rich in cocoa butter (Awad and Marangoni, 2006). Differences in behavior can be ascribed to the chemical composition of cocoa butter, especially regarding its TAG distribution (Shukla, 2006). Depending on the origin of the cocoa almonds and on the fermentation and refining conditions, the chemical composition may vary and this reflects mainly on the crystallization rate and hardness characteristics during the processing steps and may involve a progressive quality loss once the product is in consumers' hands, usually associated with re-crystallization of the fat phase, such as the appearance of fat bloom (McGauley and Marangoni, 2002; Rousseau, 2007). Studies show that cocoa butter produced in regions with a cold climate has higher amounts of diunsaturated TAGs and unsaturated fatty acids, resulting in an increase in softness which may compromize its crystallization behavior, especially during industrialization and distribution in tropical areas (Lipp and Anklam, 1998; Lannes et al., 2003). In Brazil, a partial solution and common commercial practice for this problem includes a major use of cocoa butter blends obtained from mixtures of almonds from different origins, in order to achieve a more consistent product (Timms, 2003). The investigation of the distinct crystallization patterns of cocoa butter produced in Brazil, in relation to the behavior found for industrial standard blends might identify simpler alternatives suitable for standardizing product quality. The purpose of this investigation was to complement the results already disclosed in Part I of this work (Ribeiro et al., 2012) by establishing a relationship among triacylglycerol composition, crystallization kinetics, microstructure and polymorphism for three industrial standard cocoa butter blends and Brazilian cocoa butter samples obtained from three different Brazilian states.

\section{MATERIALS AND METHODS}

\subsection{Material}

Raw materials. Cocoa butter samples were selected as presented in Part I of this paper (Ribeiro et al., 2012).

\subsection{Analytical Methods}

Polarized light microscopy. Samples were melted at $70{ }^{\circ} \mathrm{C}$ and a drop was placed on a pre-heated glass slide $\left(70^{\circ} \mathrm{C}\right)$ and covered with a coverslip. Slides were prepared in triplicate for each sample. Slides were incubated at the temperature of analysis $\left(15^{\circ} \mathrm{C}\right)$ for 180 minutes. The crystal morphology was evaluated using polarized light microscopy (Olympus, model BX 50, San Jose, USA) coupled to a digital video camera (Media Cybernetics, Bethesda, USA). The slides were placed on the support plate (Mettler Toledo, FP82 Microscope Hot Stage, Columbus, USA) and held at $15{ }^{\circ} \mathrm{C}$. The images were captured by the application of Image Pro-Plus version 7.0 (Media Cybernetics, Bethesda, USA), using polarized light and with a magnification of 40 times. For each slide, three visual fields were captured, representative of the crystals observed. The evaluation parameters selected for a quantitative analysis of the images, performed through the software Image Pro-Plus version 7.0 (Media Cybernetics, Bethesda, USA), were the mean diameter of the crystals and the the percentage of crystallized areas (Campos, 2005; Silva et al., 2009).

Crystallization isotherm. The samples were melted $\left(70^{\circ} \mathrm{C}\right.$ for $\left.15 \mathrm{~min}\right)$ and kept in a high precision dry bath (Tcon 2000, Duratech, Carmel, USA) at $60{ }^{\circ} \mathrm{C}$ for complete destruction of their crystalline history. The increase in solid fat content due to crystallization time was monitored by a Nuclear Magnetic Resonance spectrometer (RMN) Bruker pc120 Minispec (Silberstreifen, Rheinstetten, Germany), with the reading compartment stabilized at $15{ }^{\circ} \mathrm{C}$. The data acquisition was automatic, with measurements taken every minute, for 90 minutes. The characterization of the crystallization kinetics was performed according to the induction period $\left(\tau_{\mathrm{SFC}}\right)$ - relative to the onset of the formation of crystals, maximum solid fat content $\left(\mathrm{SFC}_{\max }\right)$ and relative time to obtain $50 \%$ of the maximum content of solids ( $\left.t_{1 / 2 S F C \max }\right)$. The induction time was obtained graphically and reflects the time required for a stable nucleus to be formed in the liquid phase (Campos, 2005). The original Avrami equation was used to model the crystallization process:

$$
\frac{\operatorname{SFC}(t)}{\operatorname{SFC}(\infty)}=1-e^{-k t^{\prime \prime}}
$$

Where: SFC( $t$ ) describes the solid fat content (\%) as a function of time, $\operatorname{SFC}(\infty)$ is the asymptotic value of the solid fat content, $k$ is the constant of Avrami $\left(\mathrm{min}^{-n}\right)$, which takes into account both the nucleation and the rate of crystal growth and $n$ is the Avrami exponent, which indicates the mechanism of crystal growth (McGauley and Marangoni, 2002). The equation was linearized in order to obtain the values of $k$ and $n$. The analyses were performed in duplicate for each sample.

$X$-ray diffraction. The polymorphic form of the crystals was determined according to the AOCS 
method Cj 2-95 (AOCS, 2004). Analyses were performed on a Philips diffractometer (PW 1710, Almelo, The Netherlands), using Bragg-Bretano geometry $(\theta: 2 \theta)$ with radiation $\mathrm{Cu}-\mathrm{k} \alpha(\mathrm{k}=1.54056 \AA$, tension of $40 \mathrm{KV}$ and current of $30 \mathrm{~mA}$ ). Measurements were obtained with steps of $0.02^{\circ}$ in $2 \theta$ and an acquisition time of 2 seconds, with scans of 5 to $40^{\circ}$ (scale 2 $\theta$ ). The samples were melted at $70{ }^{\circ} \mathrm{C}$ and stabilized in an oven at $25^{\circ} \mathrm{C}$ for 20 days. Analyses were performed at $25^{\circ} \mathrm{C}$, according to the procedure described by Marangoni (Marangoni, 2005). Identification of the polymorphic form was carried out from the short spacing characteristic of crystals (Schenck and Peschar, 2004; Marangoni, 2005).

Differential scanning calorimetry. The characteristic temperatures of the polymorphic transitions of the cocoa butter samples were determined in a Differential Scanning Calorimeter, heat flow type, Shimadzu, model DSC-50 (Shimadzu Corporation, Kyoto, Japan), with coupled software. Pure nitrogen (99\%), at a flow of $50 \mathrm{~mL} / \mathrm{min}$, was used as carrier gas. Aluminium capsules were used for analysis, the reference being an empty capsule. The experiments were performed according to the methodology of Luccas and Kieckbusch (2006). The mass of the samples ranged from 10 to $12 \mathrm{mg}$. The samples, inside the aluminium capsules, were placed in an oven at $70{ }^{\circ} \mathrm{C}$ for 15 minutes to ensure complete melting of the fat crystals. To induce the formation of the type I crystals, the capsules were previously immersed in liquid nitrogen for 15 seconds and then transferred to the calorimeter, where they were kept at $-45^{\circ} \mathrm{C}$ for 30 minutes. Heating was conducted in two steps: first the temperature was raised to $-10^{\circ} \mathrm{C}$ at a rate of $5{ }^{\circ} \mathrm{C} /$ min and then heated up to $40{ }^{\circ} \mathrm{C}$ at a rate of $0.3{ }^{\circ} \mathrm{C}$ per min. The melting peak temperatures, corresponding to the temperatures of polymorphic transitions, were determined by the software TA-50 WS (Shimadzu, Kyoto, Japan).

\subsection{Statistics Analysis}

The statistical analyses were based on the Analysis of Variance (ANOVA) and Tukey Test to determine the significant differences of the means at a probability level of $5 \%(p<0.05)$ using Statistica 8.0 (Statsoft, USA).

\section{RESULTS AND DISCUSSION}

\subsection{Microstructure}

The microstructure level (or mesoscale) of a fat crystal network can be defined as structures with sizes between 0.5 and $200 \mu \mathrm{m}$ (Narine and Marangoni, 2005). Polarized light microscopy is the most commonly used technique for visualizing the microstructural network of fats and has been applied to elucidate differences in the texture of fat blends and to detect crystalline types or morphological changes during crystal growth. In chocolates, the crystalline network determines quality aspects, such as texture, gloss, hardness, structural stability, ease in demoulding and antiblooming properties (Awad and Marangoni, 2006; Gioielli et al., 2003). Figure 1 shows the crystalline structure of cocoa butter samples obtained by crystallization at $15^{\circ} \mathrm{C}$. Values of the mean diameter of the crystals and the percentages of crystallized areas are given in Table 1.

Expressive differences were observed among cocoa butter samples regarding the mean crystal diameter. The size varied around $6.0 \mu \mathrm{m}$ for the industrial blends. For the Brazilian cocoa butter, however, the diameters were considerably higher (8.14 $\mu \mathrm{m}$ for Braz B and $12.20 \mu \mathrm{m}$ for Braz A), with no significant difference $(p<0.05)$ among themselves, according to the Tukey Test. Braz C exhibited an anomalous $41.53 \mu \mathrm{m}$ mean diameter. The samples Blend A, Blend B, Blend C, Braz A and Braz B crystallized as disks, with granular structure composed by a large number of small sized crystals. In sample Braz $\mathrm{C}$, however, the presence of disks and spherulites was observed, characterizing a mixed morphological type. The relative percentages of crystallized areas for the five samples varied between 23 and $27 \%$ and sample Braz C, again, showed an abnormality, with a percentage below $20 \%$, indicative of a lower density crystal network (Narine and Marangoni, 2005). A higher proportion of the liquid phase, as in this specific sample, can slow the formation of crystalline nuclei, since supersaturation, necessary for initiating the crystallization process, is delayed. During the ordering of the system, higher supersaturation is needed to ensure stable nuclei formation (Sato, 2001). In Braz C sample, fewer nuclei are stable, which then grow into larger dimensions.

The microstructural behavior characterized by crystalline elements of small size and in large numbers observed for samples Blend $A$, Blend $B$, Blend $C$, Braz $A$ and Braz $B$, is especially influenced by the way cocoa butter is cooled from the liquid state because the solid-phase separation depends mainly on the cooling rate and on the initial and final temperatures applied in the process. In the liquid state, the TAG molecules are in random motion. Under high degrees of supercooling, the nucleation process is very fast and the time for molecular rearrangement is insufficient to promote the formation of the more stable crystalline conformation, creating less ordered solids. At the same time, there is a fast increase in viscosity, which limits the transfer of heat and mass. The nucleation rate increases exponentially with the increase of supersaturation, while the growth rate is linearly proportional to supersaturation and therefore, the crystal number increases and the crystal size decreases when crystallization occurs at low temperatures, as in the case of this study. Thus, the combination of these factors promotes the formation of systems with numerous and small 

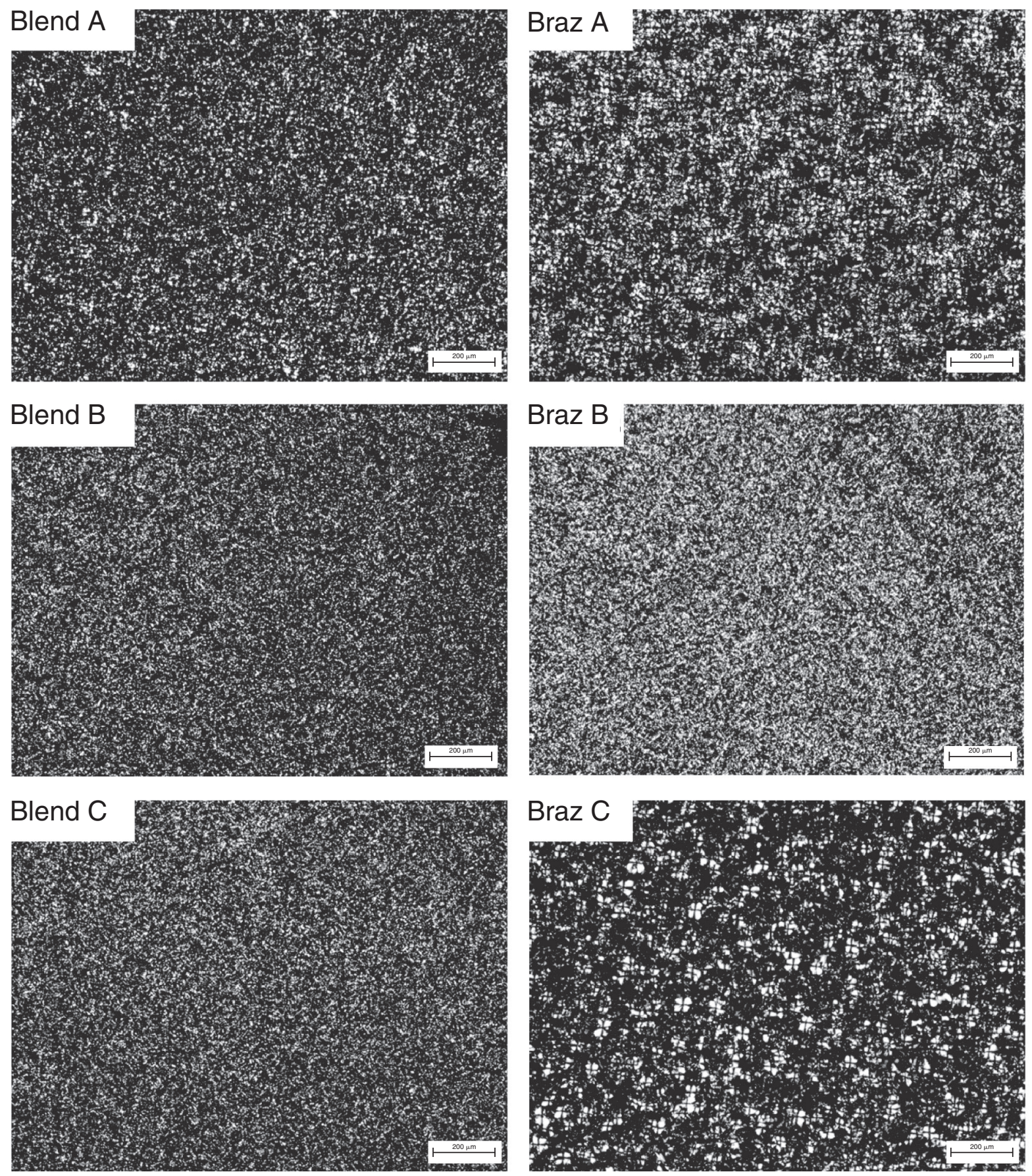

Figure 1

Images obtained by static crystallization of cocoa butter samples at $15^{\circ} \mathrm{C}$ for 180 minutes. The bar represents $200 \mu \mathrm{m}$.

sized crystals, typical of crystalline networks with a granular appearance and high density (McGauley and Marangoni, 2002; Rodrigues-Ract et al., 2010). According to Kloek et al. (2000), the presence of a great number of small crystals impairs the fat superior hardness in comparison to the hardness provided by a smaller number of larger crystals. The later situation is also associated with undesirable sensorial characteristics, known as a sandy feeling in the mouth, which may be detected when crystals exceed the average diameter of 30 um (Herrera et al., 1998). This observation, together with the results for microstructure obtained for sample Braz C, show different solidification behavior, corroborating results observed in our previous study, in which this sample showed the lowest hardness, expressed as yield value, among all samples studied (Ribeiro et al., 2012).

The microstructural characteristics of lipid systems are not determined just by the crystallization conditions, however. The triacylglycerol (TAG) composition of cocoa butter influences its solidification properties, including morphology, number and size distribution of crystals (McGauley and Marangoni, 2002). According to Shi et al. (2005), the predominant TAG class in the fat controls its 
Table 1

Mean crystal diameter and percentages of crystallized area of cocoa butter samples, obtained by static crystallization at $15^{\circ} \mathrm{C}$ for 180 minutes

\begin{tabular}{lcc}
\hline Sample & $\begin{array}{c}\text { Mean crystal } \\
\text { diameter }(\mu \mathrm{m})\end{array}$ & $\begin{array}{c}\text { Crystallized area } \\
(\%)\end{array}$ \\
\hline Blend A & $6.33 \pm 0.31^{\mathrm{d}}$ & $23.44 \pm 1.50^{\mathrm{c}}$ \\
Blend B & $5.80 \pm 0.62^{\mathrm{d}}$ & $26.18 \pm 0.22^{\mathrm{a}}$ \\
Blend C & $6.14 \pm 0.18^{\mathrm{d}}$ & $26.20 \pm 6.49^{\mathrm{a}}$ \\
Braz A & $12.20 \pm 0.14^{\mathrm{b}}$ & $23.99 \pm 3.20^{\mathrm{b}}$ \\
Braz B & $8.14 \pm 0.33^{\mathrm{c}}$ & $23.52 \pm 1.13^{\mathrm{b}}$ \\
Braz C & $41.53 \pm 1.71^{\mathrm{a}}$ & $19.95 \pm 6.45^{\mathrm{d}}$ \\
\hline
\end{tabular}

Means \pm standard deviation of the replications. Means followed by the same letter within a column indicate significant difference $(p<0.05)$ by Tukey's test.

mesoscale pattern. It is reasonable to suppose, therefore, that the higher level of disaturatedmonounsaturated TAGs $\left(S_{2} U\right)$ in the samples Blend $A$, Blend B, Blend C and Braz B, according to Part I of this paper (Ribeiro et al., 2012), is the vector responsible for the smaller crystalline diameter of these samples and for the formation of a denser granular network. Additionally, the high level of monosaturated-diunsaturated TAGs $\left(U_{2} S\right)$, with lower melting points, observed in samples Braz A and Braz $C$, might be related to higher mean diameters and less cohesive crystalline networks (as shown in Figure 1) due to the longer time required for the nucleation of these samples (Ribeiro et al., 2012).

Studies indicate that the temperature of $20{ }^{\circ} \mathrm{C}$ is critical to determine the relationship between the microstructure and the polymorphism of cocoa butter. In a detailed study, Awad and Marangoni (2006) observed that below this temperature, cocoa butter has a granular morphology, representative of the $\beta$ ' polymorph, while crystallization under higher temperatures promotes the formation of clusters of spherulites and needle-shaped crystals with high polymorphic stability. Although a wide variety of morphologies can exist for a particular polymorphic form, recent studies on the microstructure of cocoa butter, using polarized light microscopy, indicate that under crystallization at $15^{\circ} \mathrm{C}$, the $\alpha$ polymorph is stable only during 20 minutes, which corresponds to approximately $8 \%$ of the crystallized area. Above this value, as the results observed in this work after 90 minutes of crystallization, the granular structure is indicative of the presence of $\beta$ ' polymorph, for the samples Blend $A$, Blend $B$, Blend $C$, Braz $A$ and Braz $B$. The simultaneous presence of larger disks and spherulites (close to $50 \mu \mathrm{m}$ ) for Braz $\mathrm{C}$ evidences, therefore, a possible polymorphic $\beta^{\prime} \rightarrow \beta$ transition, confirming a distinct crystallization pattern for this sample (Rousseau, 2007; Kellens et al., 1992). This behavior may be related to the development of crystals with undesirable dimensions hence weaker crystalline networks, which causes a decay in consistency and loss of gloss in chocolate-based products (Timms, 2003).

\subsection{Crystallization kinetics}

Changes in the crystallization kinetics of cocoa butter are followed by a modification of its crystalline network, which greatly affects its rheological properties (Foubert et al., 2005). Figure 2 shows the crystallization isotherms obtained at $15{ }^{\circ} \mathrm{C}$ for the cocoa butter samples. The curves show a sigmoidal shape characteristic of the Avrami model, with an initial period without changes, followed by a rapid increase of the crystalline mass fraction (Herrera et al., 1999). Table 2 shows the $\tau_{\mathrm{SFC}}$, $\mathrm{SFC}_{\max }, \mathrm{t}_{1 / 2 \mathrm{SFC} \text { max }}$ values and Avrami parameters (and their coefficients of determination, $\mathrm{R}^{2}$ ), for the six cocoa butter samples.

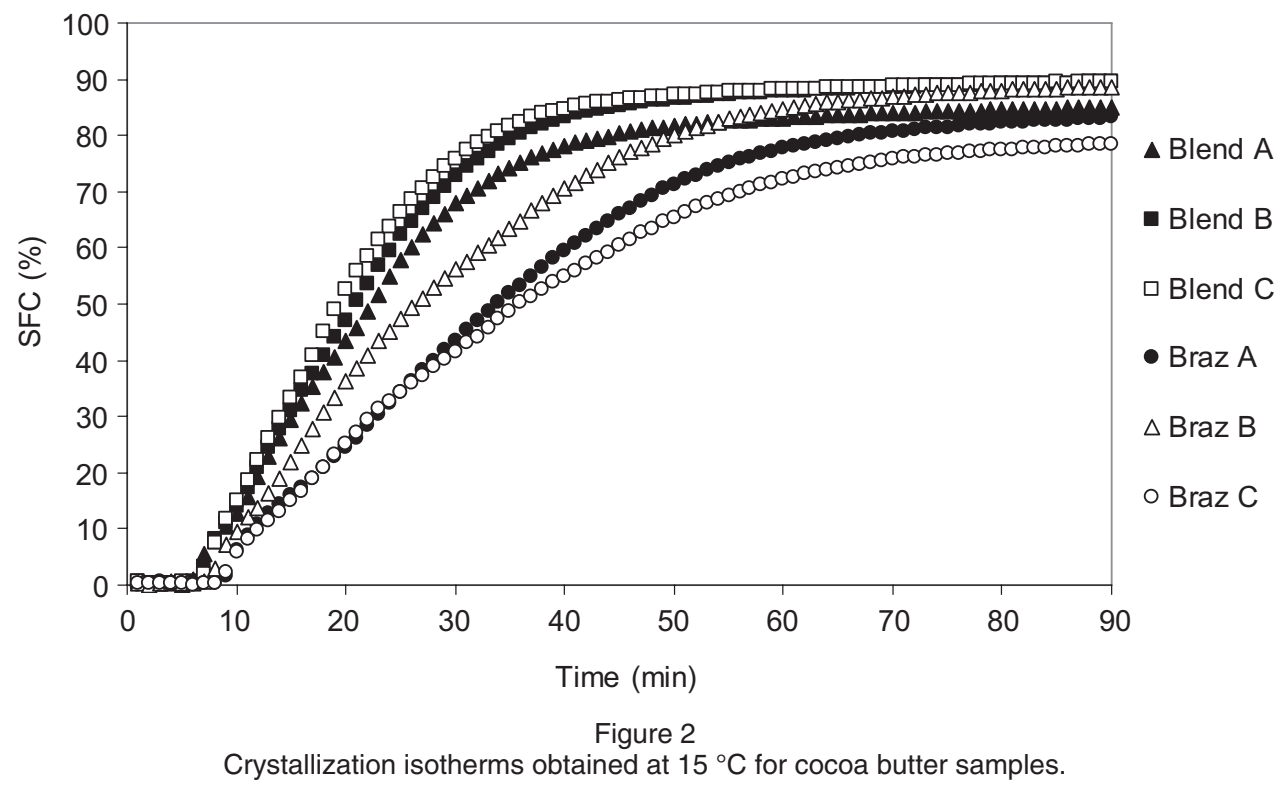


Table 2

Induction period $\left(\tau_{\mathrm{SFC}}\right)$, maximum solid fat content $\left(\mathrm{SFC}_{\max }\right)$, time required to obtain $50 \%$ maximum solid fat content $\left(\mathrm{t}_{1 / 2 \mathrm{SFCmax}}\right)$, Avrami constant $(k)$, Avrami exponent $(n)$ and respective coefficients of determination $\left(R^{2}\right)$ for the cocoa butter samples

\begin{tabular}{lcccccc}
\hline Sample & $\tau_{\mathrm{SFC}}(\min )$ & $\mathrm{SFC} \max (\%)$ & $\mathbf{t}_{1 / 2 \mathrm{SFC} \max }(\mathbf{m i n})$ & $\mathbf{n}$ & $\boldsymbol{k} \cdot \mathbf{1 0}^{\mathbf{4}}\left(\mathbf{m i n}^{-\mathrm{n}}\right)$ & $\mathbf{R}^{\mathbf{2}}$ \\
\hline Blend A & $6 \pm 0.0^{\mathrm{c}}$ & $85.0 \pm 0.4^{\mathrm{c}}$ & $19.7 \pm 0.5^{\mathrm{d}}$ & 2.08 & $9.73 \pm 0.52^{\mathrm{b}}$ & 0.95 \\
Blend B & $6 \pm 0.0^{\mathrm{c}}$ & $89.5 \pm 0.2^{\mathrm{a}}$ & $19.2 \pm 0.4^{\mathrm{d}}$ & 2.10 & $11.32 \pm 0.23^{\mathrm{a}}$ & 0.93 \\
Blend C & $6 \pm 0.0^{\mathrm{c}}$ & $89.5 \pm 0.1^{\mathrm{a}}$ & $17.9 \pm 0.2^{\mathrm{e}}$ & 2.09 & $11.23 \pm 0.16^{\mathrm{a}}$ & 0.94 \\
Braz A & $8 \pm 0.0^{\mathrm{b}}$ & $83.2 \pm 0.2^{\mathrm{d}}$ & $28.9 \pm 0.1^{\mathrm{a}}$ & 2.00 & $4.68 \pm 0.48^{\mathrm{d}}$ & 0.99 \\
Braz B & $7 \pm 0.0^{\mathrm{b}}$ & $88.7 \pm 0.1^{\mathrm{b}}$ & $23.5 \pm 0.2^{\mathrm{c}}$ & 2.00 & $7.56 \pm 0.39^{\mathrm{c}}$ & 0.95 \\
Braz C & $8 \pm 0.0^{\mathrm{a}}$ & $78.4 \pm 0.2^{\mathrm{e}}$ & $28.2 \pm 0.2^{\mathrm{b}}$ & 2.67 & $2.78 \pm 0.55^{\mathrm{e}}$ & 0.96 \\
\hline
\end{tabular}

Means \pm standard deviation of the replications. Means followed by the same letter within a column indicate significant difference $(p<0.05)$ by Tukey's test.

The $\tau_{\mathrm{SFC}}$ values ranged from 6 minutes (all industrial blends) to 7 or 8 minutes for the Brazilian samples. These results indicate, therefore, that the different manufacturers were able to obtain a precise standardization of the raw material mixture. In a detailed study on cocoa butter crystallization, Chaiseri and Dimick (1995) found that the content of some specific TAGs presents a pronounced effect on the $\tau_{\mathrm{SFC}}$ value. Samples with higher levels of $\mathrm{POO}$ and StOO and lower concentrations of POSt and StOSt showed longer induction periods. This tendency was also found in the present study. The results found in Part I of this paper show that the contents of $\mathrm{POO}+\mathrm{StOO}$ species are higher than $6.4 \%$ for the Brazilian samples and below $3.9 \%$ for the blends. The levels of POSt + StOSt, on the other hand, ranged from 62.5 to $65.6 \%$ for the Brazilian samples and 64.4 to $70.0 \%$ for the blends (Ribeiro et al., 2012). POO and StOO could act as competitors in the crystallization of the sn-2oleoyl-di-saturated TAGs, which suggests that the addition of specific triacylglycerols could modulate the $\tau_{\mathrm{SFC}}$ values, characteristic of the solidification process of cocoa butter (Chaiseri and Dimick, 1995; Himavan et al., 2006).

The $\mathrm{SFC}_{\max }$ values ranged from 78.4 to $89.5 \%$ for all samples. The sample Braz $\mathrm{C}$ exhibited a particularly low $\mathrm{SFC}_{\max }$ compared to the industrial blends, as well as their national correspondents. These results characterize a high degree of supercooling for cocoa butter, generally associated with $\tau_{\mathrm{SFC}}$ values below 10 minutes and $\mathrm{SFC}_{\max }$ close to $90 \%$ (McGauley and Marangoni, 2002). The study of cocoa butter crystallization kinetics is generally performed under a low degree of supercooling (at temperatures above $20^{\circ} \mathrm{C}$ ). In this study, the use of higher temperatures showed to be impracticable due to the long time required for the experimental determinations as a function of the higher monosaturated-diunsaturated $\left(\mathrm{U}_{2} \mathrm{~S}\right)$ TAG contents of the Brazilian samples (Ribeiro et al., 2012). To ensure comparable results, the crystallization kinetics were studied at $15^{\circ} \mathrm{C}$ for all six cocoa butter samples.

The values of $t_{1 / 2 \mathrm{SFCmax}}$ shown in Table 1 indicate that this parameter differentiates the blends from the Brazilian samples in a more precise way. The $t_{1 / 2 \text { SFCmax }}$ values for the blends were below 20 minutes and higher than 23.5 minutes for the Brazilian samples, indicating lower crystalline growth rates for the latter ones. Metin and Hartel (1998) reported $t_{1 / 2 S F C \max }$ equal to 23.2 minutes for isothermal crystallization at $15^{\circ} \mathrm{C}$ of cocoa butter from the Ivory Coast, a similar result to that observed for sample Braz $B$, from the state of Bahia. These differences for cocoa butter results are mainly due to the distinct disaturatedmonounsaturated $\left(\mathrm{S}_{2} \mathrm{U}\right)$ TAG contents, as mentioned in Part I of this study, which influence the formation and the structuring of the crystalline network (Ribeiro et al., 2012; Himavan et al., 2006). Significant changes in the crystallization rate of cocoa butter due to differences in chemical composition can result in unacceptable physical properties, such as excessive softness and susceptibility of the chocolate to fat bloom and also difficulties during its processing, thus justifying the need for standardization of this raw material by using suitable blends which are compatible to tropical areas (Chaiseri and Dimick, 1995).

The Avrami constant, $k$, is affected primarily by the crystallization temperature and reflects the velocity of this process (Campos, 2005). The highest values for this constant were observed for the industrial blends, indicative of the higher crystallization rates of these samples. The lowest $k$ values corresponded to samples Braz $\mathrm{A}$ and Braz $\mathrm{C}$, in accordance with the values observed for $t_{1 / 2 S F C \max }$.

The Avrami exponent, $n$, is sensible to the crystallization mechanism, regarding the nucleation process and the dimensionality of growth. Nucleation may be sporadic or instantaneous and the crystal growth may occur in one, two or three dimensions, characterizing the formation of crystals in the form of needles, disks or spherulites, respectively. The values of $n=3$ correspond to spherulitic growth from instantaneous nuclei or disk-shaped growth from sporadic nuclei, while the values of $n=2$ denote needle-shaped growth from sporadic nuclei or disk-shaped growth from instantaneous nuclei (McGauley and Marangoni, 
2002). Although $n$ should correspond to a whole number, fraction values are usually obtained. This deviation is primarily related to the formation of crystals with similar morphology starting from different types of nucleation (sporadic and instantaneous). Also, fractional values of the exponent $n$ may result from simultaneous development of crystals with different morphologies or even transitions between morphologies (Marangoni, 2005). The $n$ values found were between 2.00 and 2.10 for Blend $A$, Blend $B$, Blend C, Braz A and Braz B. Sample Braz C, as already observed during the microstructure and induction time evaluation, exhibits an anomalous behavior. According to Foubert et al. (2005), low $n$ values for cocoa butter crystallization at low temperatures reflect the rapid formation of numerous nuclei and small crystals as observed for the five samples with $n$ around 2.0. The crystal structures (Figure 1), composed of granular morphology characterized by small disks, confirm the $n$ values characteristic of disk-shaped growth from instantaneous nuclei. In this system, where the nucleation density is extremely high, the final development of crystals as spherulites is not usually reached and no transitions subsequent to the initial crystalline morphology occur, characterizing a highly ordered and homogeneous system (Metin and Hartel, 1998). For sample Braz C, which presents mixed crystals composed of disks and spherulites (Figure 1 ), the $n$ value equal to 2.67 is possibly related to a morphological transition between these crystal types, both originating from instantaneous nuclei, thus excluding the other possibilities proposed by the Avrami model, while confirming the different crystallization characteristics found for this sample (McGauley and Marangoni, 2002).

\subsection{Polymorphism}

In lipids, thee specific types of sub-cells are predominant and are related to the polymorphs $\alpha$, $\beta$ ' and $\beta$. The $\alpha$ form is metastable, with hexagonal packing. The $\beta$ ' form has intermediate stability and orthorhombic perpendicular packing, while the $\beta$ form has higher stability and triclinic parallel packing (Martini et al., 2006). The X-ray diffraction is used to identify crystal polymorphism, by determining the dimensions of the crystal unit and sub-cells. Due to different geometrical configurations, polymorphs diffract X-rays at different angles. In fats, high diffraction angles correspond to short spacing of the sub-cells and allow for checking different polymorphs. Short spacing can be defined as the distance between parallel acyl groups in the TAG molecule and refers to the cross-packing of the TAG chains (Garti et al., 1986; Ribeiro et al., 2009).

The X-ray patterns obtained for the cocoa butter samples are shown in Figure 3 and Table 3 presents the calculated short spacings and corresponding polymorphic forms obtained for cocoa butter samples. All samples analyzed were presented as form $\mathrm{V}$, whose characteristic short spacings are 3.65, 3.73, 3.87, 3.98, 4.22, 4.58, 5.13 and $5.38 \AA$ (McGauley and Marangoni, 2002). The set of these diffraction lines is known as the fingerprint region and is specific for each polymorph (Schenck and Peschar, 2004). According to McGauley and Marangoni (2002), the approach to form $V$ from the liquid state under static crystallization conditions can proceed by two different pathways: i) through the transition sequence I $\rightarrow$ IV, or; ii) directly from form IV, at

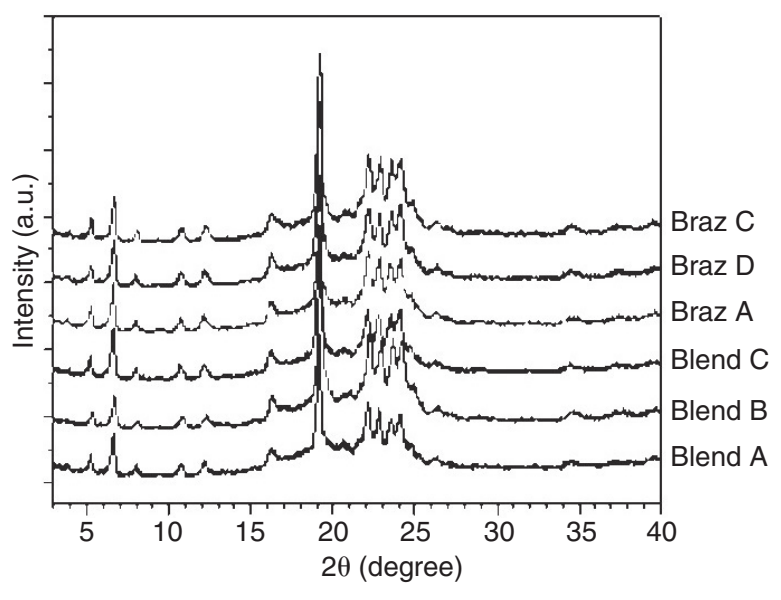

Figure 3

X-ray diffraction patterns of cocoa butter samples, crystallized at $25^{\circ} \mathrm{C}$ for 20 days.

Table 3

Short spacings and corresponding polymorphic forms of cocoa butter samples

\begin{tabular}{|c|c|c|c|c|c|c|c|c|c|}
\hline \multirow[b]{2}{*}{ Sample } & \multicolumn{9}{|c|}{ Short spacing* $(\AA)$} \\
\hline & 3.6 & 3.7 & 3.8 & 4.0 & 4.2 & 4.6 & 5.1 & 5.4 & Polymorph \\
\hline Blend A & $3.68 \mathrm{~s}$ & $3.77 \mathrm{~s}$ & $3.89 \mathrm{~s}$ & $4.01 \mathrm{~s}$ & $4.29 w$ & $4.62 \mathrm{vs}$ & $5.14 \mathrm{vw}$ & $5.38 \mathrm{~m}$ & V \\
\hline Blend B & $3.66 \mathrm{~s}$ & $3.76 \mathrm{~s}$ & $3.86 \mathrm{~s}$ & $4.00 \mathrm{~s}$ & $4.25 w$ & 4.61vs & $5.09 \mathrm{vw}$ & $5.42 \mathrm{~m}$ & V \\
\hline Blend C & $3.69 \mathrm{~s}$ & $3.77 \mathrm{~s}$ & $3.89 \mathrm{~s}$ & $4.02 \mathrm{~s}$ & $4.24 w$ & 4.63vs & $5.13 \mathrm{vw}$ & $5.43 \mathrm{~m}$ & V \\
\hline Braz A & $3.69 \mathrm{~s}$ & $3.77 \mathrm{~s}$ & $3.88 \mathrm{~s}$ & $4.01 \mathrm{~s}$ & $4.24 w$ & 4.62vs & $5.15 \mathrm{vw}$ & $5.44 \mathrm{~m}$ & V \\
\hline Braz B & $3.68 \mathrm{~s}$ & $3.76 \mathrm{~s}$ & $3.88 \mathrm{~s}$ & $4.00 \mathrm{~s}$ & $4.25 w$ & $4.62 \mathrm{vs}$ & $5.16 \mathrm{vw}$ & $5.44 \mathrm{~m}$ & V \\
\hline Braz C & $3.67 \mathrm{~s}$ & $3.76 \mathrm{~s}$ & $3.88 \mathrm{~s}$ & $4.00 \mathrm{~s}$ & $4.28 w$ & 4.62vs & $5.13 v w$ & $5.43 \mathrm{~m}$ & V \\
\hline
\end{tabular}

* The relative intensity is noted as very strong (vs), strong (s), medium (m), weak (w), or very weak (vw). 
crystallization temperatures between 20 and $26^{\circ} \mathrm{C}$, a condition in which form $\mathrm{V}$ can be kept stable for several weeks. The absence of the polymorph $\mathrm{VI}$ is in line with expectations, since the $\mathrm{V} \rightarrow \mathrm{VI}$ transition is very slow compared with other polymorphic transformations and may take four months to be completed, being accelerated by temperature fluctuations (Wille and Lutton, 1966; Larsson, 1994).

\subsection{Polymorphic transitions (DSC)}

When a fa is heated, it may exhibit multiple melting phases and each re-crystallization step represents the transition from a less stable polymorphic form to a more stable one. The peak transition temperature is indicative of the polymorphic form of a crystal because the most stable crystalline form has a higher melting point (Zeitoun et al., 1993). The heating and cooling rates (scanning) have a primary effect on the shape of the curves obtained by DSC. Under low rates $\left(1^{\circ} \mathrm{C} /\right.$ min or less), the limited heat load allows for the accomplishment of molecular rearrangements. Some thermal events, such as the melting of previously existing polymorphic forms, polymorphic transformations and the subsequent melting of newly formed polymorphs can be observed when the sample is slowly melted (Campos, 2005).

The rate of polymorphic transitions in cocoa butter defines processing conditions and is directly related to the stability of chocolate during storage. Studies on cocoa butter polymorphism determined specific melting temperatures for each polymorphic form. However, there is a great discrepancy among the data presented in the literature regarding the number of crystalline forms and their respective melting points. A survey indicates that the melting temperatures of polymorphs I, II, III, IV, V and VI lie, respectively, within the following limits: 11.318.0 ${ }^{\circ} \mathrm{C}$; $15.1-24.2{ }^{\circ} \mathrm{C}$; 20.0-28.0 ${ }^{\circ} \mathrm{C}$; 21.1-33.0 ${ }^{\circ} \mathrm{C}$; 27.4-35.0 ${ }^{\circ} \mathrm{C}$ and 29.0-36.2 ${ }^{\circ} \mathrm{C}$ (Vaeck, 1960; Duck, 1964; Wille and Lutton, 1966; Huyghebaert and Hendrickx, 1971; Chapman et al., 1971; Lovergren et al., 1976; Merkens and Vaeck, 1980; Van Malssen et al., 1999; Timms, 2003; Narine and Marangoni, 2005; Luccas and Kieckbusch, 2006).

Figure 4 shows the DSC melting thermograms obtained for the six cocoa butter samples. The thermal behavior profiles of the samples indicate similar tendencies regarding polymorphic transition patterns. The different peaks detected represent the polymorphic transitions and the melting peak temperatures provide indications on different crystalline habits. The first endothermic peak (a), with low intensity, corresponds to the melting of form I, with a low melting point. This polymorph is characterized by high instability and its detection is difficult. Form I can be obtained only from complete melting followed by fast cooling at significantly low temperatures (McGauley and Marangoni, 2002; Luccas and Kieckbusch, 2006). The second endothermic peak (b) shows the melting of form II, while the third peak (c) can be related to the melting of forms III and IV, corresponding to the set of $\beta$ ' type sub-cells. Regarding both peaks, an endothermic deviation of the baseline in a very

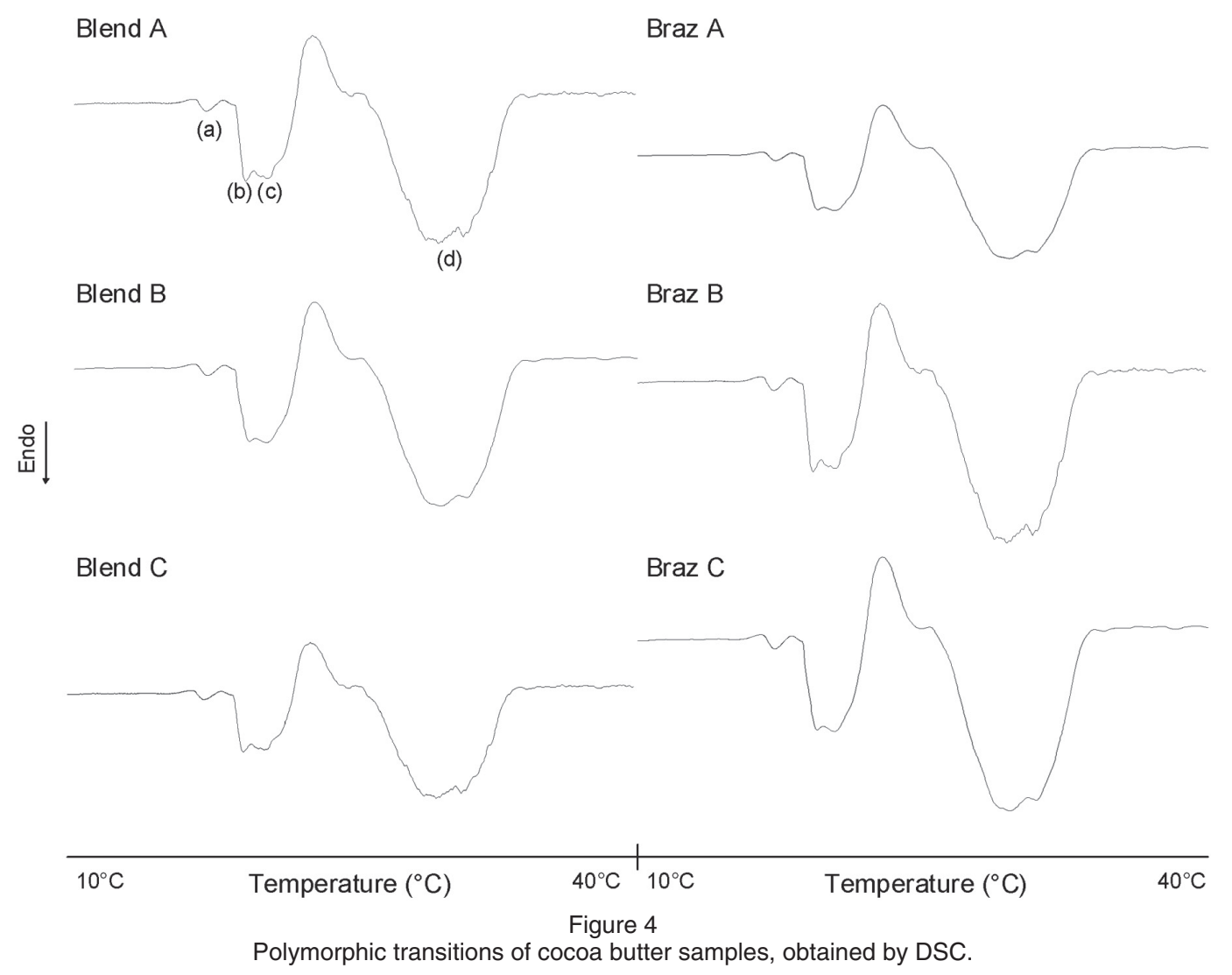


broad temperature range, between 18.0 and $21.5{ }^{\circ} \mathrm{C}$, can be observed, with concomitant presence of them in the bottom of this endotherm. The reduced variability in TAG composition, as found in cocoa butter, can result in significantly narrow peaks during the melting of the samples, especially in relation to the crystalline forms with close melting intervals. The location of this baseline deviation, associated with the wide melting range found, suggests the possibility of an overlap of the peaks corresponding to polymorphs II and III + IV. The differentiation of these polymorphs can be difficult mainly regarding the melting of crystalline types with the same sub-cell pattern, as crystals III and IV. In the present study, they were considered as a single crystalline element in the interpretation of the results (Sato, 2001). Using X-ray diffraction, Van Malssen et al. (1996) also had difficulties to distinguish the polymorphs III and IV and even questioned the independent existence of these crystalline forms. Loisel et al. (1998), using DSC (scanning rate equal to $0.1{ }^{\circ} \mathrm{C} / \mathrm{min}$ ), found that crystallization of form IV begins before the complete crystallization of form III, which causes an overlap effect or close proximity of the corresponding peaks. The significant exothermal increase in enthalpy after point (c) indicates the creation of a polymorph with high thermal stability, characteristic of form V. Therefore, the occurrence of a broad peak (d) at temperatures between 24 and $34{ }^{\circ} \mathrm{C}$ provides evidence for the melting of this crystalline type. Similar melting thermograms of cocoa butter, obtained at a scanning rate of $0.1^{\circ} \mathrm{C} / \mathrm{min}$, were also observed by Loisel et al. (1998). The wide temperature interval between the onset and the endset of the melting may be related to the low scanning rate employed in the analysis, which usually causes the segregation of different types of TAGs, according to the levels of unsaturated fatty acid in their molecules during the organization process and formation of crystals (Aronhime, 1988).

Figure 5 correlates the temperatures of the polymorphic transitions obtained for cocoa butter samples, corresponding to the peak temperatures in the thermograms. The polymorphic transition temperatures of the crystalline phases I, II, III + IV and $V$ were within 15.90 and $16.80{ }^{\circ} \mathrm{C} ; 19.58$ and $20.16{ }^{\circ} \mathrm{C}$; 20.02 and $21.94{ }^{\circ} \mathrm{C}$ and 28.72 and $33.58{ }^{\circ} \mathrm{C}$, respectively. The results show good agreement with the temperature ranges reported in the literature. The transition temperatures related to the melting of $\beta$ ' form, represented by the combined forms III + IV, however, are lower than the mean temperatures registered in the literature, but still within these limits (Timms, 2003; Narine and Marangoni, 2005; Luccas and Kieckbusch, 2006).

The six different cocoa butter samples showed very similar polymorphic transition patterns. This demonstrates that variations in their chemical composition, especially regarding TAG profile, exert negligible effect on this behavior. For the Braz $C$ sample, however, the temperatures of the polymorphic transitions, with the exception of form $\mathrm{V}$, were slightly lower, an indication of higher relative velocity in these transformations, in agreement with the results previously discussed on microstructure and Avrami parameters obtained for this sample.

\section{CONCLUSIONS}

The study of triacylglycerol composition, microstructure, crystallization kinetics and polymorphism of Brazilian and industrial standardized cocoa butter samples provided evidence for establishing relationships between the chemical compositions and their general crystallization characteristics. Particularly, the properties concerning microstructure and crystallization kinetics were related to trisaturated, disaturated-monounsaturated and monosaturated-diunsaturated triacylglycerol contents of cocoa butter samples. However, a similar trend was not observed with respect to polymorphic behavior, which indicates that the chemical composition of cocoa butter exerts little or no influence on the parameters of the crystal habit and melting temperature of polymorphs. The analysis

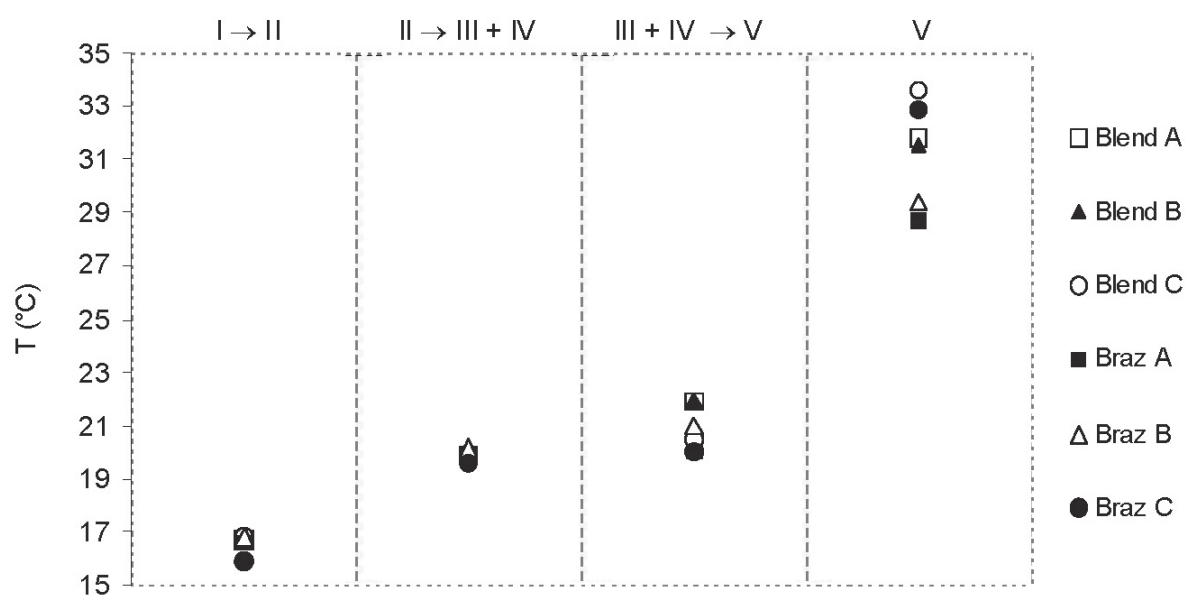

Polymorphic forms (transitions)

Figure 5

Polymorphic transition temperatures of cocoa butter samples. 
of the results allowed for differentiating the samples regarding the velocity and order of the crystallization process. The blends with industrial standards were characterized by higher crystallization rates and more homogeneous microstructure distribution, with the formation of smaller crystals and consequently, crystalline networks with high density and stability, suitable for use in tropical areas. Brazilian samples showed lower crystallization rates, forming crystals with larger sizes, which imply weaker crystalline networks. The sample from Espírito Santo state showed distinct solidification behavior, associated with an unstable crystalline network, which may reflect possible technological problems when used in warmer climates. Among Brazilian samples, the cocoa butter obtained from the Amazonas state presented the closest similarity to the industrial blends.

\section{ACKNOWLEDGEMENTS}

To the Fundação de Amparo à Pesquisa do Estado de São Paulo (FAPESP - Proc. 2009/53006-0 and Proc. 2010/18504 -7) for the financial support.

\section{REFERENCES}

AOCS. American Oil Chemists' Society. 2004. Official methods and recommended practices of the Am. Oil Chem. Soc.. AOCS Press, Urbana, USA.

Aronhime JS. 1988. Application of thermal analysis (DSC) in the study of polymorphic transformations. Thermochim. Acta 134, 1-14.

Awad TS Marangoni AG. 2006. Ingredient interactions affecting texture and microstructure of confectionery chocolate, en McPherson A, Gaonkar AG (Eds.) Ingredient Interactions: Effects on Food Quality. CRC Press, Boca Raton, págs. 424-471.

Campos R. 2005. Experimental Methodology, en Marangoni AG (Ed.) Fat Crystal Networks. Marcel Dekker, New York, págs. 267-349.

Chaiseri S, Dimick PS. 1995. Dynamic crystallization of cocoa butter. Characterization of simple lipids in rapid- and slow-nucleating cocoa butters and their seed crystals. J. Am. Oil Chem. Soc. 72, 1491-1496.

Chapman GM, Akehurst EE, Wright WB. 1971. Studies using programmed temperature X-ray diffraction and differential scanning calorimetry. J. Am. Oil Chem. Soc. 48, 824-830.

Duck W. 1964. The measurement of unstable fat in finished chocolate. Manuf. Confectioner 35, 67-72.

Foubert I, Vanrolleghem PA, Dewettinck K. 2005. Insight in model parameters by studying temperature influence on isothermal cocoa butter crystallization. Eur. J. Lipid Sci. Technol. 107, 660-672.

Foubert I, Dewettinck D, Walle DV, Dijkstra AJ, Quinn PJ. 2007. Physical properties: structural and physical characteristics, en Gunstone FD, Dijkstra AJ (Eds.) The Lipid Handbook. CRC Press, Boca Raton, págs. 471-508.

Garti N, Schlichter J, Sarig S. 1986. Effect of food emulsifiers on polymorphic transitions of cocoa butter. J. Am. Oil Chem. Soc. 63, 231-236.

Gioielli LA, Simões IS, Rodrigues JN. 2003. Crystal morphology and interactions of binary and ternary mixtures of hydrogenated fats. J. Food Eng. 57, 347-355.
Herrera ML, Falabella C, Melgarejo M, Anon MC. 1998. Isothermal crystallization of hydrogenated sunflower oil: I - nucleation. J. Am. Oil Chem. Soc. 75, 12731280.

Herrera ML, Falabella C, Melgarejo M, Anon MC. 1999. Isothermal crystallization of hydrogenated sunflower oil: II - growth and solid fat content. J. Am. Oil Chem. Soc. 76, 1-6.

Himavan C, Starov VM, Stapley AGF. 2006. Thermodynamic and kinetic aspects of fat crystallization. Adv. Colloid Interface Sci. 122, 3-33.

Huyghebaert A, Hendrickx H. 1971. Polymorphism of cocoa butter, shown by differential scanning calorimetry. Lebensmittel-Wissecschaft and Technologie 4, 59-63.

Kellens M, Meeussen W, Reynaers H. 1992. Study of the polymorphism and the crystallization kinetics of tripalmitin: A microscopic approach. J. American Oil Chem. Soc. 69, 906-911.

Kloek W, Walstra P, van Vliet T. 2000. Crystallization kinetics of fully hydrogenated palm oil in sunflower oil mixtures. J. Am. Oil Chem. Soc. 77, 389-398.

Lannes SCS, Medeiros ML, Gioielli LA. 2003. Physical interactions between cupuassu and cocoa fats. Grasas Aceites 54, 253-258.

Larsson K. 1994. Lipids: Molecular Organization, Physical Functions and Technical Applications. The Oily Press, Dundee, UK.

Lipp M, Anklam E. 1998. Review of cocoa butter and alternative fats for use in chocolate - part A. Compositional data. Food Chem. 62, 73-97.

Loisel C, Keller G, Lecq G, Bourgaux C, Ollivon M. 1998. Phase transitions and polymorphism of cocoa butter. J. Am. Oil Chem. Soc. 75, 425-439.

Lovergren NV, Gray MS, Feuge RO. 1976. Polymorphic changes in mixtures of confectionery fats. J. Am. Oil Chem. Soc. 53, 83-88.

Luccas V, Kieckbusch TG. 2006. Estudo comparativo do polimorfismo da gordura de cupuaçu e da manteiga de cacau por calorimetria diferencial de varredura (DSC). Braz. J. Food Technol. 9, 63-68.

Martini S, Awad T, Marangoni AG. 2006. Structure and properties of fat crystals networks, en Gunstone FD (Ed.) Modifying Lipids for Use in Food. Woodhead Publishing, Cambridge, págs. 142-169.

Marangoni AG. 2005. Fat Crystal Networks. Marcel Dekker, New York, USA.

McGauley SE, Marangoni AG. 2002. Static crystallization behavior of cocoa butter and its relationship to network microstructure, en Marangoni AG, Narine SS (Eds.) Physical Properties of Lipids. CRC Press, Boca Raton, págs. 85-123.

Merkens GV, Vaeck SV. 1980. Etude du polymorphisme du beurre de cacao par calorimétrie DSC. Lebensm. Wiss. Technol. 13, 314-317.

Metin S, Hartel RW. 1998. Thermal analysis of isothermal crystallization kinetics in blends of cocoa butter with milk fat or milk fat fractions. J. Am. Oil Chem. Soc. 75, 1617-1624.

Narine SS, Marangoni AG. 2005. Microstructure, en Marangoni AG (Ed.) Fat Crystal Networks. Marcel Dekker, New York, págs. 179-255.

Ribeiro APB, Basso RC, Grimaldi R, Gioielli LA, Gonçalves LAG. 2009. Instrumental methods for the evaluation of interesterified fats. Food Anal. Method 2, 282-302.

Ribeiro APB, Claro da Silva R, Gioielli LA, de Almeida Gonçalves MI, Grimaldi R, Gonçalves LAG, Guenter Kieckbusch T. Physico-chemical properties of Brazilian cocoa butter and its industrial blends. Part 
I - Chemical composition, solid fat content and consistency. Grasas Aceites 63, 79-88.

Rodrigues-Ract JN, Cotting LN, Poltronieri TP, Silva RC, Gioielli LA. 2010. Comportamento de cristalização de lipídios estruturados obtidos a partir de gordura do leite e óleo de girassol. Ciência Tecnol. Aliment. 30, 258-267.

Rousseau D. 2007. The microstructure of chocolate, en McClements DJ (Ed.) Understanding and controlling the microstructure of complex foods. CRC Press, Boca Raton, págs. 649-690.

Sato K. 2001. Crystallization behavior of fats and lipids: a review. Chem. Eng. Sci. 56, 2255-2265.

Schenck H, Peschar R. 2004. Understanding the structure of chocolate. Radiat. Phys. Chem. 71, 829-835.

Shi Y, Liang B, Hartel RW. 2005. Crystal morphology, microstructure, and textural properties of model lipid system. J. Am. Oil Chem. Soc. 82, 399-408.

Shukla VKS. 2006. Cocoa Butter, Cocoa Butter Equivalents, and Cocoa Butter Substitutes, en Akoh CC (Ed.) Handbook of Functional Lipids. CRC Press, Boca Raton, págs. 279-307.

Silva RC, Cotting LN, Poltronieri TP, Balcão VM, Almeida DB, Gonçalves LAG, Grimaldi R, Gioielli LA. 2009. The effects of enzymatic interesterification on the physicalchemical properties of blends of lard and soybean oil. LWT - Food Sci. Technol. 42, 1275-1282.

Timms RE. 2003. Confectionery Fats Handbook. The Oily Press, Bridgwater, UK.

Vaeck V S 1960. Cocoa butter and fat bloom. Manuf. Confectioner 15, 35-74.

Van Malssen K, Langevelde AV, Peschar R, Schenk H. 1999. Phase behavior and extended phase scheme of static cocoa butter investigated with real-time X-ray powder diffraction. J. Am. Oil Chem. Soc. 76, 669676.

Van Malssen K, Peschar R, Schenk H. 1996. Real-time $\mathrm{X}$-ray powder diffraction investigations on cocoa butter II. The relationship between melting behaviour and composition of $\beta$-cocoa butter. J. Am. Oil Chem. Soc. 73, 1217-1223.

Wille RL, Lutton ES. 1966. Polymorphism of cocoa butter. J. Am. Oil Chem. Soc. 43, 491-496.

Zeitoun MAM, Neff WE, List GR, Mounts TL. 1993. Physical properties of interesterified fat blends. J. Am. Oil Chem. Soc. 70, 467-471.

Recibido: 10/6/11 Aceptado: 8/9/11 